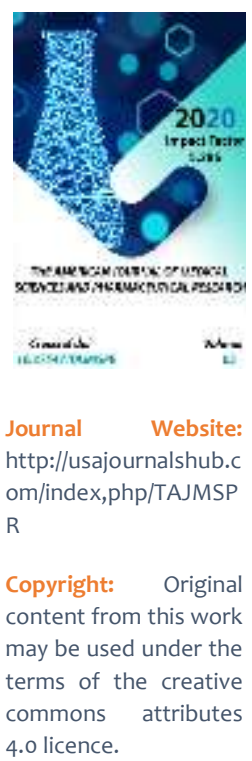

\title{
Clinical Course Of Non-Specific Aortoartheritis (Disease Takayasu) (Casefrompractice)
}

\author{
Tuxtayeva Mashxura Muxiddinovna \\ Assistant Of The Department, 2-Pediatrics And Neonatology Course, Samarkand State Medical \\ Institute, Uzbekistan
}

\section{ABSTRACT}

This article discusses the issues of early diagnosis of non-specific aortoarteritis are not generally accepted and therefore remain relevant. Takayasu syndrome (non-specific aortoarteritis) is an autoimmune inflammatory disease that affects the aorta and its branches, belongs to the group of systemic vasculitis, is characterized by the development of productive inflammation in the wall of large arteries leading to their obliteration, there is no pulsation due to frequent cases of loss of pulse in the upper extremities. The course of the disease is progressive with periodic exacerbations and deterioration of blood circulation in ischemic organs, as well as an unfavorable prognosis. Modern data on the etiology, pathogenesis, and clinical picture of Takayasu syndrome are presented. An important role in the diagnosis of non-specific aortoarteritis is played by computer and magnetic resonance imaging, as well as ultrasound examination of vessels that can detect typical signs of stenosis or aneurysm of the arteries. Treatment of the disease with the use of drugs aimed at suppressing the activity Of b cells of the immune system, as well as with the use of an IL- 6 receptor inhibitor, is discussed. In order to attract the attention of General practitioners to a rare rheumatological problem - Takayasu aortoarteritis - the results of their own observations are presented. The clinical picture of the disease in a child is described.

\section{KEYWORDS}

Takayasu syndrome, etiology, clinic, diagnosis.

\section{INTRODUCTION}

In Russia, the study of this disease is devoted to the work of S. P. Abugova,(1) A.V. Pokrovsky.(2). the Increase in the frequency of detection of NA is explained not only by improved diagnostics, but also by an absolute increase, which is particularly relevant.To date, 
the most relevant hypothesis is the autoimmune Genesis of NAA in the first set out by R. D. Yudige (3). a frequent combination of NA with Crohn's disease and ulcerative colitis has been Observed. This disease is characterized by a slow progressive course over many years, occurring with remissions and relapses.Symptoms: malaise, fever, sleep disorders, weight loss, joint pain, fatigue, accompanied by anemia and increased ESR.

\section{MATERIALS AND METHODS}

The material for the examination was the case histories of a patient who was under observation and treatment in the 1st children's city hospital for several years from 2014 to 2019.

\section{RESEARCH RESULT}

This disease was characterized by a slowprogressive course over many years, occurring with remissions and relapses significantly impairing the patient's quality of life. According to the mother, the child was born on 2/3/2008. He grew up and developed as a weak child and lagged behind in physical development. Since the age of 4 , the doctor discovered that the child has a high blood pressure of $180 / 110 \mathrm{~mm}$ Hg. he has been Treated repeatedly since 2014 for chronic glomerulonephritis of the nephrotic form. From anamnesis-had hepatitis in 2014. Of the concomitant diseases, there was anemia, chronic tonsillitis, dental caries.The state of moderate severity.The skin is pale and there is no swelling.There was no edema.Subcutaneous tissue is normal .Vesicular respiration in the lungs .Cor tones are muted.The heart area is not changed .Appetite is reduced, the tongue is moist and clean.Swallowing is free, $b / b$. the Stomach is rounded, symmetrical, painless, regular stool. Urinates $b / b$, urine is yellow, clean. He was examined in the city of Tashkent in 2016 in
June, where angiography, excretory urography were performed, and aortoarteritis was diagnosed.Angiography showed some divergence, a change in the outgoing renal artery from the aorta, and a decrease in blood flow. Ultrasound showed the phenomenon of hydronephrosis, glomerulonephritis.Renal ultrasound: DMN -chronic nephritis ultrasound of the adrenal glands :hypertrophy of the adrenal glands. Glomerulonephritis of both kidneys .Hydronephrosis of the right kidney.Echodoppler:biliary tract, signs of cholecystitis.Aortic angiography some deviation of changes in the renal arteries from the aorta.The patient was examined and treated annually at the 1st children's city hospital. According to the mother, the patient's constant complaints were lagging in physical development, headaches, poor appetite, and an increase in a/D 180/110 mm Hg. ECG examination: sinus arrhythmia, left ventricular hypertrophy. Ultrasound revealed adrenal hypertrophy, glomerulonephritis of both kidneys, hydronephrosis of the right kidney of the 1st degree, and signs of cholecystitis. Dopplerography from 05.08.2016 of the renal vessels revealed: the renal blood flow is depleted, on both sides there is a moderate decrease in the linear velocity of blood flow along the segmental arteries on both sides, and the left vertebral artery is bent. Ultrasonography of the adrenal glands expelled dichromatism.

MSCT(multispiral computed tomography) was performed on 18.09.2015:MSCT-signs of internal increasing hydrocephalus .Periventricular edema.

MSCT(multispiral computed tomography) was performed on 02.11.2015:MSCT examination of the kidneys, ureters, and bladder revealed no volume formation. 
MSCT(multispiral computed tomography) was performed on 04.12.2015:MSCT examination of the adrenal glands revealed no pathological changes.

In the Republican specialized scientific and practical medical center of endocrinology, the results of a radioimmune study showed Cortisol $630.2 \quad \mathrm{nmol} / \mathrm{l}$ from 21.12.2015.Aldosterone 170.2 PG/mol .Renin 17.6 PG / ml. ACTH $26.7 \mathrm{ng} / \mathrm{ml}$.

The results of the General blood test showed er-3,8. Hb-95, lake-9,7.PAL-4\%, SEG-42, EOS-4\%, L-43\%, mon-7\%.ESR-14mm/hour.The General analysis of urine specific gravity 1005.protein 1.33, LEU-3.7, er-4.5. cylinders -2.3.

Urine according to Nechiporenko leukocytes 4 thousandEr 2 thousand in sight.Urine on zimnitsky day diuresis 800, night 1080.The specific gravity of urine is 1010 .

Blood biochemistry protein 50, bilirubin-17, Calcium-1,7, cholesterol -4,6. creatinine0,198.Sugar -9,9. urea-12,8.

A / D 180/110 mm Hg ECG: sinus arrhythmia left ventricular hypertrophy 150

The child was examined from 2015 MSCT with conclusion at MSCT 02.10.2015 by contrast of the renal arteries:No structural changes were found in the abdominal aorta and its branches. Dopplerography of major vessels 5/08 2016 Conclusion: When imaging the gaps of OSA from both sides enough to the left, the deformation stroke of the ICA in the proximal segment with the local $\mathrm{h} / \mathrm{d}$, a significant gradient of velocities (60-108) moderate hypoplasia of the right vertebral artery, the bend of the left vertebral artery AP and the bone canal of the transverse process of the 5 th cervical vertebra cap-M - $0.7 \mathrm{~mm}$ is not changed.
Biochemical blood tests showed from 04.12.2015 in the blood sodium135.1.Potassium-3.43.Chlorine $62.0 \mathrm{mmol} / \mathrm{l}$.

Analyses from 06,05,2015 year:alkaline phosphatase $86 \quad$ U/L.Cortisol 130.0 nmol/l.Adrenocorticotropic hormone 8.3 PG / $\mathrm{ml}$.

Since 05.08.2016, dopplerography of the main vessels has been performed, where dopplerography of the OSA lumen on both sides has sufficient left deformations of the ICA course in the proximal segment with a local $g$ / d significant velocity gradient (60180).Moderate hypoplasia of the right vertebral artery, bending of the left vertebral artery at the entrance of the bone channel of the transverse process of the $\mathrm{V}$-cervical vertebra.Cl-M $0.7 \mathrm{~mm}$ is not changed.

Echocardiography from 05.08.2016 of the septum without defects.

2016 showed moderate LV dilatation, wall hypertrophy is not observed, and the valves are intact. partitions without defects.Doppler: abnormal flows are not recorded. Heart rate 105 in $\min . \mathrm{FV} 78 \%$.

MSCT revealed no abnormal changes in the adrenal glands.

The results of the research were the following diagnosis: Aortoarteritis, Takayasu disease, chronic glomerulonephritis, nephrotic form of mesangio-proliferative type, period of partial remission. The child received a course of antibiotic therapy, prednisone, cyclophosphane, amlodipine, irbesan, thrombo-ACC, cyclophosphamide, azathioprine, methotrexate, curantil, vitamins, and herbal medicine.

As a result of observation and treatment in dynamics, the child's condition progressively 
worsened in April 2017, the child died of kidney failure.

Thus, the disease is associated with exposure to an infectious-allergic agent and autoimmune aggression. Deposited in the vascular walls, immune complexes cause granulomatous inflammation and narrowing of the internal diameter of the vessel, which contributes to thrombosis. The effectiveness of conservative therapy, surgical treatment, and prognosis for life is entirely determined by the detection of this insidious disease at the initial stages of its development.

\section{CONCLUSION}

For early diagnosis of non-specific aortoarteritis, it is necessary to expand the range of examinations at the early stages of the disease development and solve the issue of early surgical correction of the disease treatment, especially in children with renal pathology and high blood pressure.

\section{REFERENCES}

1. Takayasu M. A case with peculiar changes of the central retinal vessels. ActaSocietatisophthalmologicaeJapon icae / M. Takayasu. - Tokyo, 1908. - P. 12: 554 .

2. Martorell F. El sindrome de obliteracion de los troncossupraaor-ticos. MedicinaClinica / F. Martorell, J. F. Tersol. - Barcelona, 1944. - P. 2: 26-30.

3. Pathogenesis of Takayasu's arteritis: a 2011 update / L. Arnaud,J. Haroche, A. Mathian, G. Gorochov, Z. Amoura // Autoimmun Rev. - 2011. Vol. 11(1). - P. 61-67.

4. Takayasu arteritis. A study of 32 North American patients / S. Hall, W. Barr, J.T. Lie, A.W. Stanson, F.J. Kazmier // Hunder. Medicine
(Baltimore). - 1985. - Vol. 64(2). - P. 89-99.

5. Phillip R. Mortality in systemic vasculitis: a systematic review /

R. Phillip, R. Luqmani // ClinExpRheumatol. - 2008. - Vol. 26.

- Vol. 5. - Suppl 51. - S94-104.

6. Clinical characteristics and outcomes of Takayasu's arteritis: analysis of 108 patients using standardized criteria for diagnosis, activity assessment, and angiographic classification / M.C. Park, S.W. Lee, Y.B. Park, N.S. Chung // Lee Scand J Rheumatol. - 2005. - Vol. 34(4). - P. 284-292.

7. Maksimowicz-McKinnon K. Limitations of therapy and a guarded prognosis in an American cohort of Takayasu arteritis patients /

K. Maksimowicz-McKinnon, T.M. Clark, G.S. Hoffman // Arthri-tis Rheum. - 2007. Vol. 56(3). - P. 1000-1009.

8. Quality of life of patients with Takayasu's arteritis / [C.J. Abu-larrage, M.B. Slidell, A.N. Sidawy, et al.] // Vasc. Surg. - 2008.

- Vol. 47(1). P.131-136.

9. Quality of life in patients with Takayasu's arteritis is impaired and comparable with rheumatoid arthritis and ankylosing spondylitis patients / [S. Akar, G. Can, O. Binicier, K. Aksu, B. Akinci, D. Solmaz, et al.] // Clin.Rheumatol. -2008. - Vpl. 27(7). - P. 859-865.

10. Angiographic findings of Takayasu arteritis: new classification / [A. Hata, M. Noda, R. Moriwaki, F. Numano] // Int.J.Cardiol. - 1996. - Vol. 54. - S155163.

11. Покровский А.В. Диагностика и лечение неспецифического 
аортоартериита / А.В. Покровский, А.Е. Зотиков, В.Л. Юдин.

- М.: Ирис, 2002. - 144 C.

12. Johnston S.L. Takayasu arteritis: a review / S.L. Johnston, R.J. Rock, M.M. Gompels // Journal of clinical pathology. - 2002. - Vol. 55. - № 7. - P. 481-486.

13. The American College of Rheumatology 1990 criteria for the classifi-cation of Takayasu arteritis / [W.P. Arend, B.A. Michel, D.A. Bloch, et al.] // Arthritis Rheum. - 1990. - Vol. 33(8). - P. 1129-1134.

14. Miller D.V. The pathology of largevessel vasculitides. ClinEx-pRheumatol / D.V. Miller, J.J. Maleszewski // Jan-Feb. $-2011$.

- Vol. 29. - 1 Suppl 64. - S92-98.

15. Andrews J. Takayasu's arteritis-recent advances in imaging offer promise / J. Andrews, J.C. Mason // Rheumatology (Oxford). - 2007. - Vol. 46(1). - P. 6-15

16. Schmidt W.A. Use of ultrasonography and positron emission tomography in the diagnosis and assessment of largevessel vas-culitis / W.A. Schmidt, D. Blockmans // CurrOpinRheumatol.

- 2005. - Vol. 17(1). - P. 9-15. 